\title{
REPÚBLICA DOMINICANA, ECONOMÍA Y POLÍTICA AL TERMINO DEL SIGLO XX
}

\author{
BERNARDO VEGA *
}

\section{Resumen:}

Centra su reflexión en explicar los principales factores que en los últimos diez años han contribuído a generar los principales cambios operados en la sociedad dominicana, tanto a nivel económico como social y la relación de éstos en nuestras relaciones con Haití.

Palabras Claves: Relaciones Internacionales, Intercambio Económico.

\footnotetext{
Bernardo Vega Economista, investigador y empresario, presidente de la
} Fundación Cultural Dominicana. 
Se me ha pedido que hable sobre " República Dominicana; economía y política al término del siglo $\mathrm{XX}$ ", pero pretendo hacer uso de mis conclusiones para elucubrar sobre un asunto especifico que sé que es de interés del público aquí presente.

Si hace unos 100 años se le hubiera pedido a alguien que describiera la economía dominicana, hubiera dicho que era una economía productora y exportadora de azúcar, café, cacao y tabaco.

Si en la década de los setenta se hubiera hecho una pregunta similar, es decir casi 100 anos después, se hubiera dado la misma respuesta.

Sin embargo, en los últimos 10 años, desde principios de la década de los años ochenta, en nuestro país ha tenido lugar un cambio estructural violento que ha modificado totalmente la economía dominicana. Somos ahora un país cuya principales exportaciones son el turismo, los ingresos de zona franca y las remesas de los dominicanos ausentes. Ya aquellas famosas exportaciones de ayer juegan un papel muy reducido en nuestra economía.

Creo importante enfatizar una docena de factores que no sólo han surgido últimamente, sino que en los pocos años que faltan de este siglo, y los del que viene, pienso se acentuarán.

Considero importante primero mencionar el hecho de que nuestro campesino no constituye la mayoría del pueblo, pues desde hace algunos años nuestra población urbana es mayoritaria. Aproximadamente un $60 \%$ de los dominicanos vivimos en las ciudades, lo que implica que el mismo, o un mayor volumen de alimentos para consumo interno, o para exportación, tendremos que producirlo con menos mano de obra. 
El segundo factor es que creo que va a continuar y va a acrecentarse la diáspora, el éxodo de dominicanos hacia el exterior. Esa diáspora es un factor común a todas las islas del Caribe, sin excepción, pero considero que va a ocurrir aquí el mismo fenómeno que sucedió en Puerto Rico. Desde muy principios de este siglo, los boricuas han tenido libertad para emigrar hacia los Estados Unidos. Sin embargo, esa emigración sólo se acrecentó, de manera importante, en la década de los años 50 , porque un campesino, un jibaro cortador de caña, se sentía muy incómodo buscando trabajo en las grandes urbes del norte. mientras que, con el proceso de industrialización de los años 50 (muy parecido al ensamblaje de zonas francas del Santo Domingo de hoy), el puertorriqueño se dio cuenta que ya podía encontrar trabajo en New York, recibiendo allí, además, mucha mayor remuneración. En consecuencia, el proceso mismo de la industrialización acentuó la tendencia migratoria. Creo que a medida que Santo Domingo contimúe su proceso de urbanización e industrialización, el cual es muy similar al de Puerto Rico, se incentivará la tendencia de la emigración. Eso tiene ya y tendrá un enorme impacto, y no solo en términos de remesas. El otro día estuve en un sitio público. había que hacer fila, y ésta se estaba violando consistentemente, como es costumbre hacerlo entre nosotros, pero, de pronto, un señor muy humilde se manifestó en forma muy violenta, explicando que él estaba haciendo fila y no quería se la violentaran. Me le acerqué y le pregunté si vivía en New York. Su respuesta fue afirmativa.

$Y$ es que estamos importando la disciplina de los países industrializados y eso, poco a poco, hasta afecta nuestra vida cotidiana.

Un tercer factor es la acentuación del hecho de que una proporción cada vez mayor de nuestra producción esta en el sector de los servicios. Eso implica una disminución en la importancia de los sectores primarios, como son la agricultura, la pecuaria y la 
tradicional industria de sustitución de importaciones. Las zonas francas y el turismo, al igual que para muchos otros países del Caribe, son ya nuestros principales elementos de crecimiento y dinamismo.

Un cuarto factor, igualmente común a todo el caribe, sin excepción, es la disminución en la producción de azúcar, lo que conlleva un menor aporte de ese sector a la generación de divisas, empleos e ingresos fiscales.

Un quinto factor creo que lo es la tendencia hacia la importancia de la agroindustria tecnificada de exportación. El pugilato entre el conuco para autoconsumo y la agroindustria de exportación lo ganara la agroindustria.

Un sexto factor es la aceptación regional del recetario ortodoxo del Fondo Monetario Internacional, como mecanismo para efectuar el ajuste. Un cambio en los países industrializados, como sería, por ejemplo, la victoria de Clinton, bien podría modificar lo que se ha llamado " el consenso de Washington ", a través del cual se le señala a todo el mundo subdesarrollado la receta única bajo la que se puede escribir algún tipo de ayuda Internacional. Pero es probable que esa tendencia continúe e implique una mayor orientación dominicana hacia las exportaciones y hacia un nivel de protección industrial y un nivel arancelario más reducidos.

El séptimo aspecto es que cada día va a tener lugar una mayor competencia por una mano de obra dominicana cada vez.más escasa. Cada día va a ser más dificil que se recojan las cosechas, por ejemplo. El jibaro desapareció en Puerto Rico en los años cincuenta. Aquí también eventualmente desaparecerá.

También vamos a ser testigos de una disminución de la disponibilidad de mano de obra urbana, pues menos personas 
estarán dispuestas a trabajar en residencias particulares como sivientas, por ejemplo, pues preferirán laborar en zonas francas o de turismo, o simplemente preferirán salir del país.

Un octavo factor es la necesaria decisión que tendrá que tomar el país sobre qué esquemas de integración participar: CARICOM; el mercado común centroamericano; algún tipo de acuerdo con México y Venezuela; o el brinco más largo hacia una zona de libre comercio a nivel continental. En esos esquemas muchas decisiones se toman a nivel regional y no solamente a nivel doméstico.

Un noveno factor es la creciente importancia que tendrá Europa para la República Dominicana. No solamente significa el ya pertenecer a Lomé y considerar a Bruselas tan importante como Washington, sino que el proceso mismo de los flujos turísticos provenientes de Europa está promoviendo inversiones privadas de ese régimen en nuestro país. Tenemos, además, la presencia de mano de obra Dominicana en Europa. Para los dominicanos con relación a este año de 1992, es que será el año en que babremos descubierto a Europa y no ellos a nosotros.

Un décimo factor será la tendencia, que todos esperamos que continúe, hacia la consolidación del proceso democrático en nuestro país. Y, finalmente, está el tema del narcotráfico. En la medida en que la droga continúe siendo ilegal, es probable que toda el área del Caribe, y nosotros no seríamos excepción, continuaremos siendo victimas de todo lo negativo que implica el narcotráfico.

Pero el punto, señores, que quiero ver hoy con ustedes, sobre el que quiero reflexionar ( $\mathrm{y}$ quisiera que esto fuera tra reflexión colectiva), es que todas esas once características o tendencias que he enumerado, de una forma $\mathbf{u}$ otra afectarán nuestras relaciones con Haití. Me explico: el profesor Claude Moise nos mostraba aquí 
hace unos días cómo Haití tiene un $30 \%$ de la población urbana. En este lado de la isla es un $60 \%$. Esto implica que en Haití hay más campesinos que en República Dominicana y que en la medida que esta tendencia continúe, la disparidad entre la proporción urbana-rural irá creciendo.

Una segunda reflexión es sobre el papel cada vez mayor que jugarán nuestras diásporas. Aunque no tengo estadísticas para probar mi punto, me da la impresión que la diáspora haitiana tiende a mejorar su calidad de vida en forma más rápida que la dominicana. Creo que eso es evidente en New York. Eso hará cambiar mucho el estereotipo que tiene el dominicano del haitiano, al notar cómo avanza más rápidamente en el extranjero que él mismo.

También es indudable la mayor capacidad de actuar, en términos políticos, de la diáspora haitiana que la domimicana. Mientras nosotros salimos en los periódicos norteamericanos con motivo de la violencia en Washington Heigths, la cual amenazó la Convención del Partido Demócrata, la diáspora haitiana posee peso político como para influir sobre decisiones a nivel del congreso norteamericano. Esa diáspora ha podido organizarse, ha podido lograr contactos políticos con grupos de senadores y diputados norteamericanos. En Europa también tiene una mayor capacidad, que la de los dominicanos, de manifestarse políticamente.

También existe la tendencia de los dominicanos en los Estados Unidos de asociarse más con los puertorriqueños, mientras que los haitianos lo hacen con los Jamaiquinos y con los negros norteamericanos, cuyas iglesias los auxilian a ascender en la comunidad.

Una tercera reflexión es que si la producción azucarera dominicana va a seguir disminuyendo cada día más, habrá una menor demanda 
de mano de obra haitiana para la misma, más aún si se acelera el proceso de mecanización. En la medida en que se haga más obvio que a los albores del siglo xx no es posible mantener mano de obra en una finca a base de utilizar guardianes con escopetas, para no abandonarla. Se va a hacer muy dificil a los ingenios pagar los salarios requeridos y ofrecer las condiciones sociales mínimas aceptables, como para lograr que esa mano de obra inmigrante no abandone el ingenio y se vaya a trabajar a otro lugar, donde encuentre condiciones más apropiadas.

Creo que pocos se han puesto a pensar que la industria azucarera estatal dominicana es un ejemplo muy interesante de una integración industrial lograda a despecho de su dueño, a nivel de isla, pues es una industria ubicada en la República Dominicana que usa mano de obra haitiana, pero una parte importante de su producción de azúcar se iba ilegalmente a Haití, donde, con mucha razón,se le importaba, pues era más barata que si se le trajese de un tercer país, dado el subsidio implícito en el precio interno del azúcar dominicano. En cierto sentido, el subsidio que otorgamos a través del precio interno de nuestro azúcar (y que ya no existe), era una forma de compensar los bajos salarios que se pagaban, pues ese subsidio beneficiaba al pueblo haitiano, el pueblo que facilita esa mano de obra.

Otra reflexión es el pensar si la escasez cada vez mayor de mano de obra, tanto en la zona rural como urbana de Santo Domingo, nos planteará la opción de si utilizar la mano de obra haitiana en las zonas francas $y$ en el turismo, o si la forma de mantener competitivos esos sectores utilizando mano de obra dominicana será devaluando nuestra moneda, para que los salarios pierdan valor internamente. De esa forma no se utilizaría una mano de obra extranjera a la cual se le pagaría menos, sino a una mano de obra local, competitiva tan solo a través de variaciones continuas en el tipo de cambio. 
No sé si algunos de ustedes se han enterado de que varias de las empresas de zonas francas que se han establecido últimamente en nuestro país, son fábricas que han salido de Haití por los problemas políticos en Puerto Príncipe. También valdría la pena pensar si es factible, o no el concepto de industria gemela, no entre Santo Domingo y Puerto Rico, sino entre Santo Domingo y Puerto Príncipe. Si valdría la pena pensar en industrias complementarias, donde la parte de mano de obra intensiva se efectúe en el otro lado de la isla y el resto en nuestro país, o en tres lugares: Haití, Santo Domingo y Puerto Rico.

También elucubrar si tiene sentido utilizar a los inmigrantes ilegales en nuestros conucos, nuestras cosechas, o si es más conveniente mecanizar nuestro proceso agrícola. Si es más conveniente utilizar al inmigrante ilegal como sustituto del dominicano en el servicio doméstico, o si es más conveniente no tener servicio doméstico alguno, como ya sucede, por ejemplo, en Puerto Rico.

Hay un aspecto relacionado con la apertura, la sincerización de las economías y el libre funcionamiento de las fuerzas del mercado que interesa a ambos países, pues, tal como también nos lo explicó el profesor Claude Moise, el tipo de cambio haitiano, al igual que el dominicano, está siendo determinado por las fuerzas del mercado y el Gourde, el cual, al igual que el peso dominicano, que por décadas tuvo una paridad fija, ya está fluctuando, igual que el peso dominicano. Antes, la paridad fija, era de 5 Gourdes por un dólar. Hoy día el Gourde flota y está a 10 por dólar. Eso implica que el tipo de cambio efectivo haitiano está hoy día al mismo nivel a como estaba el peso dominicano en 1983, cuando la paridad era de dos por uno. Lo anterior significa que la devaluación que está sufriendo la moneda haitiana hace más competitiva la producción local de ese país y menos atractivas las importaciones. Una de las razones por las cuales antes se exportaba mucho desde Santo 
Domingo a Haití, era simplemente porque el tipo de cambio haitiano estaba fuertemente sobrevaluado. Esas exportaciones también eran estimuladas por la existencia de subsidios en la República Dominicana para una serie de productos básicos. La combinación de un Gourde sobrevaluado y un peso dominicano subvaluado, más los subsidios, hacía muy atractiva esas transferencias de productos dominicanos hacia Hiaití.

Pero el mismo hecho de que son las fuerzas del mercado las que están determinando los tipos de cambio, facilitaría, en el futuro, cualquier tipo de coordinación de las políticas monetarias entre ambos países.

Nuestro arancel de hoy está ya mucho más cercano al nivel haitiano pues éste actualmente es bajísimo. Cuando hablamos del arancel haitiano, estamos hablando del arancel efectivo, el que realmente se paga, porque obviamente el contrabando representa una proporción alta de las importaciones en ese país. Estamos también hablando del nivel efectivo del arancel dominicano, donde también hay mucho contrabando y subvaluación.

La actual mayor cercanía entre los valores reales de los aranceles de los dos países permitiría eventualmente la adopción de un arancel común externo, ya sea para ambos países, o como parte de un arancel común de un esquema más amplio de integración.

Y esto nos lleva al tema de la integración en sí. Creo que nada más absurdo que nosotros estemos tumbando las puertas tratando de entrar a CARICOM o a Centroamérica, o pidiendo un acuerdo de libre comercio con los Estados Unidos, cuando no tenemos acuerdo de libre comercio con la otra parte de la isla que es por donde hay que comenzar.

Entonces lo de libre comercio con Haití vendrá, ya sea por decisión bilateral, o por carambola, como parte de la entrada de los dos 
países a un mismo esquema de integración económica, ya sea el centroamericano o CARICOM.

Está también el tema de Lome. Yo creo que el estar ambos países en Lomé implica muchas cosas, entre ellas la disponibilidad de recursos para inversiones productivas y para infraestructura de interés común. Imaginémonos, por ejemplo, recursos de la Comunidad Económica Europea para hacer viable una zona de turismo en el norte del pais que permita al visitante ir de Puerto Plata a Montecristy y luego a Cabo Haitiano, visitar allí la Citadelle y seguir en avión, hacia Turquilán. Este es un triángulo turístico que ya se está promoviendo, sin que exista la infraestructura.

Ustedes ven en la televisión dominicana, en el canal turístico, ofertas de paquetes que incluyen a Haití. Además, ya hay paquetes que ofertan a Santo Domingo y Cuba. Podrian, pues surgir paquetes que abarcan a Santo Domingo, Haití y Cuba. Por el lado sur, podría crearse una estructura vial de mucho potencial que permitiría al turista trasladarse de Puerto Príncipe a Barahona, pasando por los dos lagos.

$\mathrm{Y}$, asimismo, Lomé podría proveer recursos para la prospección minera. No tiene ningún sentido, por ejemplo, que se contrate aerofotometría y que el avión se detenga en la frontera y no siga haciendo el trabajo del otro lado de la misma. Los estudios de geofisica podrían hacerse a nivel de isla y no de país en país.

Hablando en prospección minera yo, a veces, me divierto con ciertas especulaciones. ¿Qué pasaría, por ejemplo, si en Haití apareciera petróleo en abundancia, si tuviéramos de vecino al "Haití Saudita"? Entonces, la República Dominicana no tendría un Acuerdo de Crédito de San José, sino un Acuerdo de Crédito de Puerto Príncipe; y cuando tuviéramos una gran crisis de balanza de pagos, tendríamos que ir a esa ciuaiad a pedir que no detengan el 
envío del petróleo. Son especulaciones interesantes, nada es imposible en este mundo.

La lista de proyectos es amplia: Desarrollos hidroeléctricos y de riego en base a ríos cuya área de influencia beneficie a ambos países; una carretera intemacional más moderna y que cubra desde Pedernales hasta Manzanillo, planes de reforestación y de salubridad a nivel de isla, etc. También está el tema del narcotráfico. Creo que si continúa este problema en ambos lados de la isla, nada va a impedir que los narcotraficantes de un lado se pongan a operar, en forma conjunta, con los de este lado, porque tendrá sentido logístico hacerlo así. Eso obligaría a la necesidad de una actuación policial conjunta. Finalmente, quiero agregar un factor o tendencia adicional a la docena ya citada por mí en este trabajo: creo que ya existe un compromiso en Santo Domingo hacia la consolidación y mantenimiento de la democracia. Ese compromiso debería de ampliarse para que nuestros partidos políticos también se comprometan a ayudar a Haití para que allí también perdure la democracia. Ese compromiso debería sustituir la actual supuesta neutralidad oficial, que realmente encubre, pienso yo, un deseo de que en Haití siga predominando un régimen de fuerza. 